\title{
Implementing of a Pilot Line of Clothing Industry under the Philosophy Lean Manufacturing
}

\author{
Flores A., Aguilar J. A., and Choque R. H., Member, IACSIT
}

\begin{abstract}
This document shows the results of the implementation of a pilot line of clothing modular where operators work standing, under the guideline of Lean Manufacturing (LM) which arises as claim to increase the productive capacity of small and medium-sized enterprises of the clothing sector in the city of Arequipa in Peru. The objective is to analyze the variations of efficiency in the change of a system of conventional production to one modular under LM.

The research is based: 1) Field study with the collection of data from a conventional line as sequence of operations, and indexes of efficiencies for its subsequent analysis and proposal for improvement in a modular line of foot. 2) Implement production cells: A study of engineering methods such as balance of line in a module, cycle time, well same to compare the influence of $L M$ in the new efficiency measures. Finally it will display the results of efficiency indicators in a minimum of $63 \%$.
\end{abstract}

Index Terms - Lean manufacturing, line balance, modular system.

\section{INTRODUCTION}

In the last decades, the manufacturing sector remains a market textile and garment competitive in the Peruvian Industry [1], what ambition it is increasing such competitiveness through engineering methods and techniques for improvement in the process of traditional clothing industry in fabric point, which in the present study is based on the implementation of a new pilot line of clothing that foot modular work under the application of philosophy LM.

LM is considered as the most important strategy for manufacturing companies wishing to achieve a world-class performance [2]. This may be viewed as a set of tools that were developed in Japan, in terms of William Edwards Deming, that sets out how discipline work stage of process of the value chain seeking to eliminate or reduce waste, to reduce operating costs and improve the velocity of the flow of the process, in other words it is a system that uses fewer resources to create at least the same results produced through the conventional systems of production, increasing the varieties of the product required by the end customer at a lower cost [3]. The fundamental principle of LM is that the product or service and its attributes must conform to what the customer wants, and to satisfy these conditions calls for the elimination of the waste or debris. At the same time the deployment reduces overall costs, particularly indirect, while

Manuscript received January 9, 2014; revised March 11, 2014.

Flores A. and Aguilar J. A. are with the Energy and Environment Institute, San Pablo Catholic University, Arequipa, Perú (e-mail: \{adaluz.flores, jose.alberto.aguilar\} @ucsp.edu.pe).

Choque R. H. is with the San Pablo Catholic University, Arequipa, Perú, (e-mail: ramiro.choque@ucsp.edu.pe). maintaining the quality standards and reducing the cycle times of manufacture [4]. This methodology represents an Americanized concept of the Toyota Production System or TPS.

For these reasons, the objective of this study is to compare the percentages of resultant efficiency by implementing a system of standing modular production or cell system in the clothing sector in the fabric cotton, by means of a line that works under the philosophy LM for the purpose of their increase the efficiency, flexibility and the profitability of the company by means of methods of engineering of pull that include the reduction of the garbage or mudas and the versatility of the workers at the workstations.

\section{LM: AN OVERVIEW}

The philosophy LM or call also agile or flexible is considered to be a set of techniques to eliminate resources without value or mudas to optimize operative processes and to reduce the costs of continuous flow of the product in the value chain [4]. It makes use of the cellular or modular system reducing the cycle time, the time in the change of product $S M E D$ and the unnecessary inventory in the process. It eliminates the production in batches with the system called push of a conventional system turning it into a pull system of a product at every station of the module [5].

It was developed by the Company Toyota since 1950 for the elimination of all the activities that absorb resources without creating value, for the purpose of improving and optimizing operative processes and reducing the costs in the product. Additionally, this philosophy is considered a compilation of the best processes of manufacture of the world, it began for the design of the automatic loom in 1902 for the Japanese Sakichi Toyoda, who allowed to visualize defects as the break of a thread. Later, in 1913 Henry Ford initiated the massive production with the line of ensamble of the Model T, which had a flow of continuous ensamble benefiting from the economies of scale. From now on, after the visit of the Japanese to the United States there appeared the concept of the supermarkets, where it was observe the way of using the ideas of the point of use, inventory management or FIFO [6].

Finally, the combination of the automatic loom, the massive production and the supermarkets gave birth to the concepts of LM, of this form we find skills as the modules or cells, just in time or also called system of production Toyota, Single-Minute Exchange of Die or SMED, kanban, layout between other some tools [7], some developed throughout this document are:

Layout/Cells: This tool allows us to organize the company, be already in cell of work or in other systems of production, 
the advisable thing a disposition is in the shape of " $U$ ". The target is an efficient flow of work, materials, persons and information [7].

Kanban: Delivery of the correct order in the precise moment. This tool allows to level the production, it helps to the line balance, by means of boards - signs that communicate the need for material and it indicates in visual form the operator that should produce another unit or quantity. This system also is known like the system that pulls, that differs from the traditional systems of inventory that push system, also works with just in time and material requirements planning or MRP.

\section{Methodology AND Results}

The application of the present item will facilitate us the comparison of productivity between the two systems of production, so it must be considered that the methodology for the measurement of efficiencies and comparison between the two systems can be applied in different companies making we implemented LM philosophy, it is important to mention that this will not detailed to minimum the transition and work done in the change to the modular system by belonging a study specific of development of the implementation. Therefore, it is proposed to follow the following order:

\section{A. Field Study and Data Collection}

It is the operational approach to collect data, analysis, planning and implementation of effective change within the conventional line to modular line .The critical problem areas and different kinds of non-value added activities were identified in this stage, the first step is selection of the critical product family, then we will be focus in analisy the line balancing and indicators as efficiency results in one of the products, in these case is a T-shirt.

It is important to work with the efficiency indicators: Production efficiency (PE) indicates us the quantity of clothes made a day between the programmed to produce, and Average Operator efficiency (OE) is the average of the efficiency of the operators at the end of the day, which is calculated by each one and all this is given by the quantity of repetitive operations done by the average of minutes of the operations between the worked minutes. Every operator can realize several operations with different repetitions. The formulas to find the values of each one are:

$$
\mathrm{PE}=\frac{\mathrm{QD}}{\mathrm{QS}} \times 100
$$

where,

PE: Production efficiency, (\%)

QD: Quantity production on the day.

QS: Quantity production scheduled.

$$
\overline{\mathrm{OE}}=\frac{\mathrm{OE}_{1}+\mathrm{OE}_{2}+\mathrm{OE}_{3} \cdots+\mathrm{OE}_{n}}{n}
$$

where

$$
\mathrm{OE}_{n}=\frac{\sum \mathrm{TO}_{1} \times \mathrm{QRO}_{1}+\mathrm{TO}_{2} \times \mathrm{QRO}_{2} \ldots+\mathrm{TO}_{n} \times \mathrm{QRO}_{n}}{\mathrm{WT}-\mathrm{BT}}
$$

where

$\overline{\mathrm{OE}}$ : Average Operator efficiency, $(\%)$

$\mathrm{TO}_{n}$ : Average time of operation $n$, (minutes)

$\mathrm{QRO}_{n}$ : Quantity of repeats the operation $n$

WT: Working time, (minutes)

BT: Break time, (minutes)

The $\mathrm{PE}$ and the $\overline{\mathrm{OE}}$ are different in a conventional system, due to the work for batches, that is to say the number of completed clothing is not equal to the work in process of the operators in its work areas.

In the Fig. 1, there is observed the layout of the conventional line that is characterized by the immobilization of the workers along the dressmaking line, each one has assigned repetitive operations in the job and can go to different rhythm being able to produce a major or less clothing quantity in process, giving like turned out difference of efficiencies of every worker.

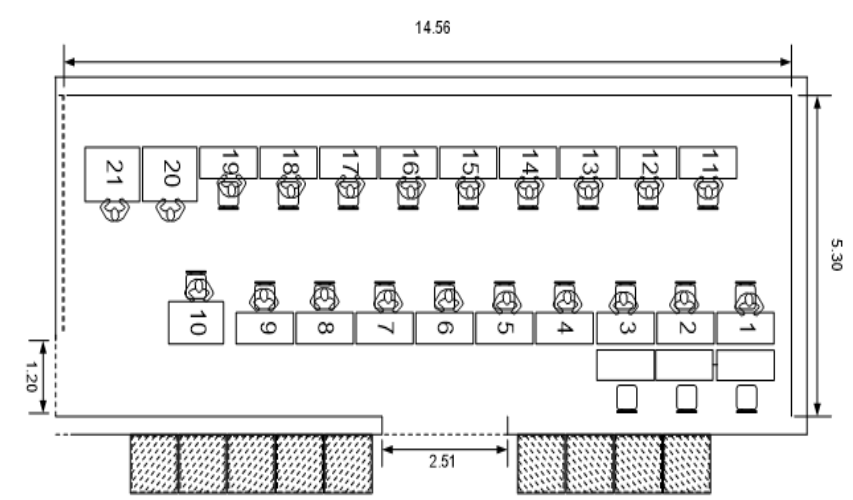

Fig. 1. Conventional layout line.

In the Fig. 2 shows the difference between $\mathrm{PE}$ and $\overline{\mathrm{OE}}$. If we analyze on the 2nd and 3rd day we observe that in the first the $\mathrm{OE}$ it is bigger in $8 \%$ than the $\mathrm{PE}$, this happens because the workers realized a major operations quantity in the clothes of which really they went out finished of the line, that is to say that they obtained a major inventory, work in process. On the 3rd it happens the opposite the PE is major in $4 \%$ why this day really there go out of the process the clothes that stayed without delivering the previous day. Likewise, we can observe the direct relation between the operators' absence with regard to the fulfillment of the quotas of production, which interrupts the ascent of the curve of learning in the line production. On the $8^{\text {th }}$ it are observed that a few indicators of $54 \%$ of $\overline{\mathrm{OE}}$ and $64 \%$ of PE on the following day these fall down to $33 \%$ and $28 \%$ respectively, due to the absence of 3 workers or $14.3 \%$ of the total absences, which makes droop the learning curve that was promoting from the first day like sample the figure.

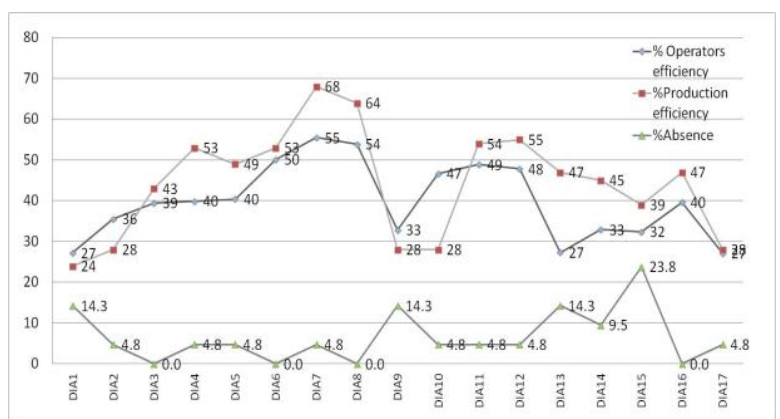

Fig. 2. Performance efficiency ( $\overline{\mathrm{OE}}, \mathrm{PE})$ and its relation to the faults. 
We observe to detail the happened in the 2nd in the Fig. 3, where the $\overline{\mathrm{OE}}$ is $36 \%$ and the $\mathrm{PE}$ is $28 \%$. The operator OP015 with $46 \%$ of efficiency, in other words wirth 213.9 worked minutes, and the OP014 with $9 \%$ of efficiency, or 41.85 minutes in production, show a deficient balance line with a difference of 172.05 minutes between an operator and other; being able to attribute such a desbalance to the quantity of assigned operations according to the observed, which diminishes the productivity inside the line and turns out to be reflected in the nonperformance of quotas of production.

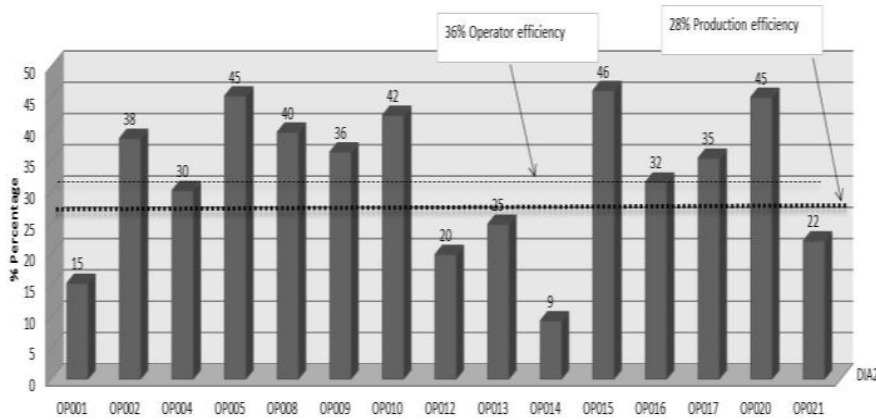

Fig. 3. Operator efficiency performance in the second day.

Finally, after evaluating the performance of a conventional system one will proceed with the implementation of techniques for the improving the line under the LM through the assembly of a modular pilot line or work cell to subsequently compare indicators.

\section{B. Study of Cell Production}

This step proposed the line balance completed in the cell production to see how well the actual work elements will fit into the desired cycle time. In addition, in the above conventional line had to be immobile operators with which it was difficult to achieve a perfect distribution of work. This new cellular system needs the moving of the operators along the areas of work, skill in different machines and operations [8]. After condition the area, installation and reliable operation of machinery and equipment, staff training in methods like line balance in a module, extension of the work station, pull system, tools of LM and changing paradigms[9], to see Fig. 4.

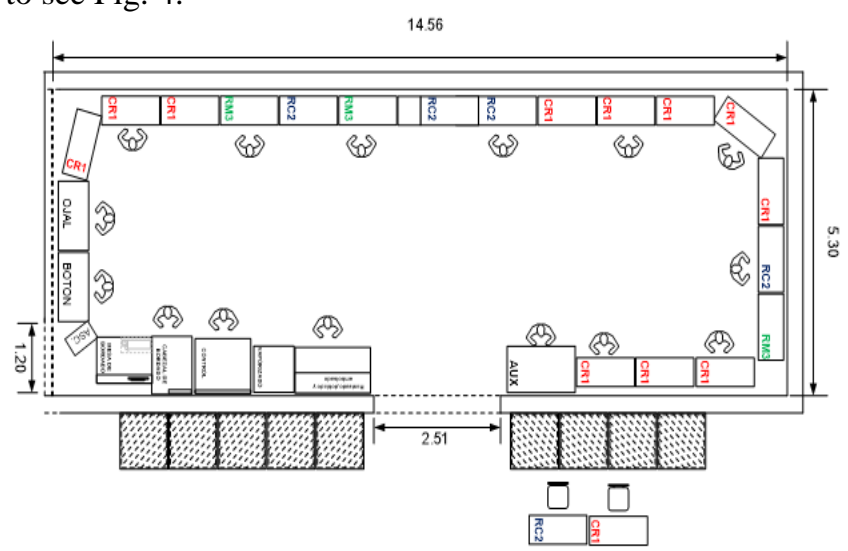

Fig. 4. Cellular layout line.

With the intention of verifying the competitive advantages that offer the production cells, opposite to conventional systems used in the industry of dressmaking, there will take as a base the simulation of the cellular system, taking as an example the same style of clothe T-shirt made in different periods of time, one in the conventional system and other in the modular system. The sequence of operations and standard times of production for unit, they appear in the Table I Example of the balance of line of the style T-shirt:

To balance the production line it is necessary to have the cycle time, average resultant from the sum of times of all the operations of the style of clothing, this time describes how long it takes to complete to specific task from start to finish, after obtaining this value it will have to reduce the times of the area of work that are out of the dressmaking cell [10], in this case the prepared area (T.PA) and the helper area (T.HA), both belong to the production line but they must not be balanced together why they would interrupt the continuous flow.

Finally, to realize the line balance we will take the operations of the assembly area (T.AA), then the operations are grouped at workstations considering the order of precedence, machinery and non-exceeding optimal time zone. The information and calculations are showed in the Table I.

$$
\mathrm{OTZ}=\frac{\mathrm{T} \cdot \mathrm{AA}}{\mathrm{LO}}
$$

where,

OTZ: Optimal time zone (minutes)

T.AA: Time of assembly area (minutes)

LO: Line operators

TABLE I: TIME OF STYLE T-SHIRT AND OPERATIONS OF A.A.

\begin{tabular}{|c|c|c|}
\hline Garment style: & \multicolumn{2}{|c|}{ T-shirt } \\
\hline Cycle time & \multicolumn{2}{|c|}{23.53 minutes } \\
\hline T.PA: Time prepared & \multicolumn{2}{|c|}{2.37 minutes } \\
\hline T.HA: Time helper & \multicolumn{2}{|c|}{2.27 minutes } \\
\hline T.AA: Time of assembly & \multicolumn{2}{|c|}{18.51 minutes } \\
\hline LO: Line operators & \multicolumn{2}{|c|}{12 operators } \\
\hline OTZ: Optimal time zone & \multicolumn{2}{|c|}{1.54 minutes } \\
\hline Operation of A.A & Machine & Time \\
\hline Operation 1 & A & 1.50 \\
\hline Operation 2 & A & 1.1 \\
\hline Operation 3 & A & 0.85 \\
\hline Operation 4 & $\mathrm{~B}$ & 0.4 \\
\hline Operation 5 & $\mathrm{C}$ & 0.6 \\
\hline Operation 6 & A & 1.19 \\
\hline Operation 7 & A & 1.18 \\
\hline Operation 8 & A & 1.35 \\
\hline Operation 9 & A & 1.07 \\
\hline Operation 10 & $\mathrm{C}$ & 0.91 \\
\hline Operation 11 & $\mathrm{C}$ & 0.91 \\
\hline Operation 12 & $\mathrm{~B}$ & 0.99 \\
\hline Operation 13 & $\mathrm{C}$ & 1.12 \\
\hline Operation 14 & B & 1.1 \\
\hline Operation 15 & A & 0.75 \\
\hline Operation 16 & A & 1.04 \\
\hline Operation 17 & A & 1.04 \\
\hline Operation 18 & $\mathrm{D}$ & 1.42 \\
\hline
\end{tabular}

The Table II shows the areas of work, obtained of the operations of the assembly area of Table I, where each color 
represents a work area for each operator to keep the line balanced. On the other hand there will be eliminated the work in lots or the system push and the pull system will be implemented with an equal work in process to one in every found work area, reducing mudas as inventory and times that do not add value, to standardize the work of operators on the production line [2]. Likewise, it is necessary the system implementation of stop called System Andom, of the production line when this initiate a unbalance, all these techniques and guidelines are contributions from LM.

TABLE II: IDENTIFY AREAS OF WORK

\begin{tabular}{|c|c|c|c|c|c|}
\hline Operation of A.A & Machine & Time & \multicolumn{3}{|c|}{12 Areas of work } \\
\hline Operation 1 & A & 1.5 & & $100 \%$ & \\
\hline Operation 2 & A & 1.1 & $3 \%$ & & $97 \%$ \\
\hline Operation 3 & A & 0.85 & $57 \%$ & & $43 \%$ \\
\hline Operation 4 & B & 0.4 & & $100 \%$ & \\
\hline Operation 5 & $\mathrm{C}$ & 0.6 & & $100 \%$ & \\
\hline Operation 6 & A & 1.19 & $14 \%$ & & $86 \%$ \\
\hline Operation 7 & A & 1.18 & $44 \%$ & & $56 \%$ \\
\hline Operation 8 & A & 1.35 & $66 \%$ & & $34 \%$ \\
\hline Operation 9 & A & 1.07 & & $100 \%$ & \\
\hline Operation 10 & $\mathrm{C}$ & 0.91 & $1 \%$ & & $99 \%$ \\
\hline Operation 11 & $\mathrm{C}$ & 0.91 & $72 \%$ & & $28 \%$ \\
\hline Operation 12 & B & 0.99 & & $100 \%$ & \\
\hline Operation 13 & $\mathrm{C}$ & 1.12 & $26 \%$ & & $74 \%$ \\
\hline Operation 14 & B & 1.1 & $65 \%$ & & $35 \%$ \\
\hline Operation 15 & A & 0.75 & & $100 \%$ & \\
\hline Operation 16 & A & 1.04 & $39 \%$ & & $61 \%$ \\
\hline Operation 17 & A & 1.04 & $88 \%$ & & $12 \%$ \\
\hline Operation 18 & $\mathrm{D}$ & 1.42 & & $100 \%$ & \\
\hline
\end{tabular}

Respect to the efficiency indicators, OE and PE are equal because the operators will be employed at the same quantity of garment that finish in the day and will maintain one garment to go to continue on the next day.

The Fig. 5 shows the global efficiency of the cell of work and its relation with the absences, showing less impact on efficiency indicators due to the support of predecessor and successor stations that lengthen their work areas as it is observed in the 10th and 11th where fault an operator in each of the days. Likewise, there is evident the increase of the efficiency in the learning curve. Should be considered that efficiencies are obtained with a smaller number of people than in a conventional system.

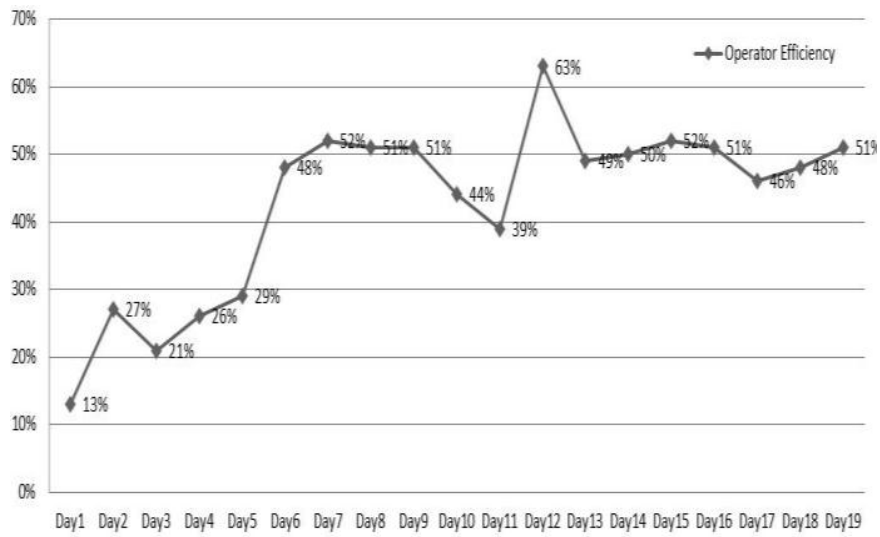

Fig. 5. Operator efficiency performance.

\section{CONCLUSION}

This document is based on the LM implementation in a company of the city of Arequipa in Peru where the studies of the mentioned philosophy are turning into one of the main techniques of improvement, for this is indispensable major studies and implementations that are adapted to the culture and to the industrial reality that the country lives.

It is important to consider the application of the skills and lineaments offered to LM to limit the waste as the inventory reduction in batches process to a clothes for workstation, the reduction of times that do not add value as dead times, due to inefficient line balanced in the conventional systems, improvement of the indicators of efficiency and the biggest fulfillment of the workloads for the consistent profitability of the company. Likewise, there appears in the document the difference between the indicators of efficiency of a conventional line and a cell of work in both the operator is the most important element to implement the change of the system and the continuous improvement in the processes. It is suggested to apply complementary tools by LM to maintain and to optimize the processes of the line of modular production.

\section{ACKNOWLEDGMENT}

The authors also wish to thank the agreement between Polos \& Cosas Sociedad de Responsabilidad Limitada and San Pablo University of Peru for motivating this research. F. A. Author thanks the Company Franky and Ricky Sociedad Anonima and the Energy and Environment Institute to promote research in the city of Arequipa in Peru. This work was supported by the Peruvian Goberment FINCYT-FIDECOM (Ministery of Production).

\section{REFERENCES}

[1] E. Ferreyros. ( Noviembre 2013). Sociedad de Comercio Exterior del Perú. [Online]. Available: www.comexperu.org.pe/archivos/semanario/SEMANARIO\%20COM EXPERU\%20729.pdf

[2] I. Lonnie, How to implement lean manufacturing, USA, 2010.

[3] J. Arrieta, V. Botero, and M. Romano, "Bechmarking about lean manufacturing in the textile sector in Medellin," Sciencia Direct. Colombia, 2010

[4] J. L. Sanchez and M. Rajadel, Lean manufacturing: La evidencia de una necesidad, 2010.

[5] A. Galgano, "Las tres revoluciones, Casa del desperdicio: Doblar la productividad con Lean Production," Ed. Diaz de Santos, 2004, España.

[6] National Association of job shops and small manufacturers, 2012.

[7] R. Cabrera, Manual de Lean Manufacturing simplificado para PYMES, 1st ed. Saarbrücken, Germany, GmbH, 2012, ch. 2, pp. 267-277.

[8] J. Restrepo, P. Medina, and E. Cruz, "Balanceo de un módulo de confección utilizando el algoritmo de Helgeson and Birnie," pp. 325-330, Universidad Tecnológica de Pereira, Colombia, 2006.

[9] K. Ann, "Adapting lean manufacturing principles to the textile industry," North Carolina State University, 2007.

[10] B. Diaz, B. Jarufe, and M. T. Noriega, Disposicion de planta, 2da edición, Fondo Editorial, Lima, pp 247-253, 2008.

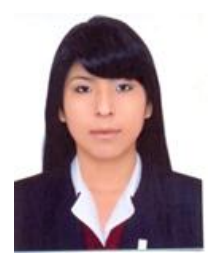

Flores A. was born on July 13, 1990. She got her bachelor degree of industrial engineering for the San Pablo Catholic University (Peru), like student exchange with Pontifical Universidade Católica do Rio de Janeiro, Brazil. Nowadays she is studying a diploma in project management with the Pontifical Catholic University of Peru and a Program in Prevencionist of Occupational 
Risks with Tecsup, Arequipa. She has experience in formulation of research projects and innovation and in project management with companies and educational institutions (San Pablo Catholic University, Polos \& Cosas, Reactivos Jeans, Flumeq).

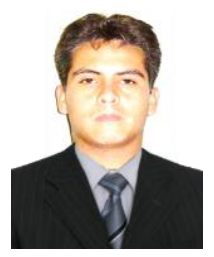

Aguilar J. A. was born on October 7, 1986. He was an industrial engineer for the San Pablo Catholic University (Peru). He received his master degree in mechanical engineering at Pontifical Catholic University of Rio de Janeiro, Brazil. With areas of development and concentration in processes of heat broadcast, thermos flask-accumulation, environmental control, new and renewable energies, thermal machines, he has knowledge in experimental methods in engineering, of control process and quality. Nowadays, he studies in Management of the Safety based on national norms, with 1 year of experience in the development of safety programs, environmental for handmade mining with production of up to 25 tons day. It has studies and experience in Formulation of Research projects and innovation, with 2 years of experience in project Management with companies of the sector (Art Atlas, Majes Tradition, Polos \& Cosas, Reactivos Jeans, Mining CEPROMET Porvenir, etc). He is currently a teacher of the San Pablo Catholic University and Engineer of Investigation of the Institute of Energy and Environment (IEM-UCSP).

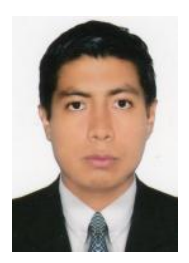

Choque R. H. was born on March 13, 1990. He got his bachelor in industrial engineering for the San Pablo Catholic University (Peru), he is a specialist in management of maintenance with Tecsup, Arequipa. Nowadays he is studyng a diploma in systems of quality management, environment and safety with the Pontifical Catholic University of Peru. $\mathrm{He}$ worked as an administrative assistant in Mecamotriz S.A.C. in the progress project development for the area of maintenance, application of methodology in improvement continue of its processes, and improving the process of service, redistribution of plant. Finally he worked as a maintenance planner in Red Electrica Andina S.A.C. 